\title{
Parâmetros genéticos e diversidade em progênies de Macaúba com base em características morfológicas e fisiológicas
}

\author{
Genetic parameters and diversity in progenies from Macaw \\ Palm based on morphological and physiological traits
}

\author{
Gisele Pereira Domiciano ${ }^{I}$ Alexandre Alonso Alves ${ }^{{ }^{*}}$ \\ Bruno Galveas LaviolaI Leo Duc Haa Carson Schwartzhaupt da Conceição ${ }^{I I}$
}

\section{RESUMO}

A obtenção de estimativas confiáveis de parâmetros genéticos, incluindo dados relacionados à variabilidade das populações sob melhoramento, é essencial para se elucidar a estrutura genética das populações e para se inferir sobre sua variabilidade genética e seu potencial de melhoramento. Nesse sentido, este trabalho teve por objetivo estimar parâmetros genéticos e a diversidade em progênies de Macaúba com base em características morfológicas e fisiológicas. Para o estudo, foram avaliadas características morfológicas e fisiológicas em 15 progênies de macaúba, em delineamento em blocos ao acaso com 5 repetições e 3 plantas por parcela, no espaçamento de $5 \times 5 \mathrm{~m}$. Não houve variabilidade para a maioria das características fisiológicas no conjunto de progênies avaliadas. Porém, verificouse variabilidade genética para os caracteres morfológicos avaliados. As famílias de macaúba agruparam-se em três grupos distintos quanto à diversidade genética, sendo a família CPAC-03 a mais divergente em relação às demais. A eficiência no uso da água e o comprimento de raquis foram as características que mais contribuíram para a dissimilaridade das famílias de macaúba.

Palavras-chave: Acrocomia aculeata, biodiesel, melhoramento genético.

\section{ABSTRACT}

Obtaining reliable estimates of genetic parameters, including data related to the existing level of variability in breeding populations is essential to elucidate the genetic structure of populations and to infer their genetic variability and potential for improvement. Therefore, this study aimed to estimate genetic parameters and diversity in progenies from Macaw Palm based on morphological and physiological traits. For that, morphological and physiological traits were evaluated in 15 macaw palm progenies (established following a random block design with 5 repetitions and 3 plants per plot - 5x5m spacing). No significant genetic variability was observed for physiological traits in the evaluated progenies. However, for the morphological traits, the existence of genetic variability was evidenced. The macaw palm families were grouped into three distinct groups based on its genetic dissimilarity, being CPAC-03, the most divergent progeny to the others. The water use efficiency and the leaflet length were the traits that contributed most to the dissimilarity of the families.

Key words: Acrocomia aculeata, biodiesel, plant breeding.

\section{INTRODUÇÃO}

$\mathrm{Na}$ produção de biodiesel, a soja se configurou nos últimos anos como a principal fonte de matéria-prima, representando em média $80 \%$ de toda a matéria-prima usada na produção do biocombustível (ANP, 2014). Porém, visando a garantir, em médio/longo prazo, alta competitividade do setor de biodiesel, torna-se importante a diversificação com a incorporação de novas fontes de matérias-primas de maior produtividade de óleo. Nesse contexto, a macaúba (Acrocomia aculeata) apresenta-se como matéria-prima potencial para a produção de biodiesel, tanto em função das elevadas produtividades de óleo previstas (entre 2500 e 4000kg ha $^{-1}$ - TEIXEIRA, 2005) como também em função de sua aptidão agroclimática, que aponta possibilidade de expansão dos plantios sem comprometer as áreas atualmente cultivadas com culturas tradicionais e/ ou alimentícias (LAVIOLA et al., 2011). Entretanto, apesar do grande potencial, a macaúba está em fase de domesticação, e grande parte das pesquisas

'Embrapa Agroenergia, Parque Estação Biológica (PqEB), s/n, W3 Norte (final), 70770-901, Brasília, DF, Brasil. E-mail: alexandre.alonso@embrapa.br. *Autor para correspondência.

"Embrapa Cerrados, Planaltina, DF, Brasil. 
concentram-se no melhoramento genético da espécie. Desse modo, a obtenção de estimativas confiáveis de parâmetros genéticos, incluindo dados relacionados à variabilidade das populações sob melhoramento, é essencial para se elucidar a estrutura genética das populações que comporão os futuros programas de melhoramento da espécie (GOMES JUNIOR et al., 2013). Características morfológicas normalmente são utilizadas para se estimara variabilidade de populações. Entretanto, como se sabe que a produtividade está diretamente relacionada ao processo de troca de gases entre as plantas e a atmosfera, parâmetros fisiológicos associados às trocas gasosas podem também ser utilizados em estudos de diversidade, pois, em grande parte, comportam-se como marcadores do status fisiológico das plantas (FLOOD et al., 2011).

Frente ao exposto, este trabalho objetivou (i) avaliar características morfológicas e (ii) fisiológicas em 15 famílias de meios-irmãos de Acrocomia aculeata, atualmente em teste na Embrapa, e posteriormente (iii) estimar parâmetros genéticos e (iv) determinar correlações entre características, de modo a inferir sobre o potencial de melhoramento da espécie. Tangencialmente, objetivou-se ainda (v) determinar quais características mais contribuem para diferenciação das progênies/indivíduos e, por fim, (vi) estimar a diversidade genética das progênies por meio do uso combinado de informações morfológicas e fisiológicas.

\section{MATERIAL E MÉTODOS}

O experimento, implantado em março de 2011 na área experimental da Embrapa Cerrados

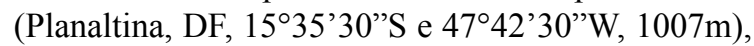
foi conduzido com 15 famílias de meios-irmãos de Acrocomia aculeata (Tabela 1). O delineamento experimental utilizado foi em blocos ao acaso, com cinco repetições, três plantas por parcela e espaçamento de $5 \times 5 \mathrm{~m}$. De acordo com a classificação de Koeppen, o clima que predomina na região é tropical úmido e seco ou de savana (Aw), ou seja, caracteriza-se por apresentar longo período de estiagem e concentração de chuvas durante o verão. O solo foi classificado como Latossolo (Oxisol), contendo altos níveis de alumínio. A fim de alcançar a correção do solo, a aplicação de calcário foi efetuada para obter uma saturação de base de $60 \%$. Em cada ano agrícola, a calagem e fertilização foi realizada conforme recomendações de PIMENTEL et al. (2011).

As seguintes características morfológicas foram avaliadas em janeiro de 2013 (período correspondente ao final da primavera e início do verão): altura da planta (em $\mathrm{m})$; comprimento da
Tabela 1 - Relação das famílias de Acrocomia aculeata avaliadas com suas respectivas origens.

\begin{tabular}{lll}
\hline Família & Acrônimo & \multicolumn{1}{c}{ Origem } \\
\hline 1 & CPAC-01 & Paranoá - DF \\
2 & CPAC-02 & Planaltina - DF \\
3 & CPAC-03 & Formosa - GO \\
4 & CPAC-04 & Carmo do Paranaíba - MG \\
5 & CPAC-05 & Carmo do Parnaíba - MG, córrego \\
6 & CPAC-06 & Matutina - MG \\
7 & CPAC-07 & Lagoa Formosa - MG \\
8 & CPAC-08 & Tiros - (MG, córrego Pimentas) \\
9 & RP002 & Rio Paranaíba-MG \\
10 & RP003 & Rio Paranaíba-MG \\
11 & RP004 & Rio Paranaíba-MG \\
12 & Acesso 280 & São Roque de Minas-MG \\
13 & Acesso 283 & Barroso-MG \\
14 & EPAMIG 1 & Itabaira-MG \\
15 & EPAMIG 2 & Itabaira-MG \\
\hline
\end{tabular}

ráquis $(\mathrm{CR}, \mathrm{em} \mathrm{cm})$; largura das ráquis $(\mathrm{LR}, \mathrm{em} \mathrm{cm})$; e número de ráquis $(\mathrm{NR}, \mathrm{n})$. A área foliar total (AFT, em $\mathrm{cm}^{2}$ ) foi estimada por meio da seguinte equação: AFT $\left(\mathrm{cm}^{2}\right)=-0,852+6,49^{*} \mathrm{a}$, onde ' $\mathrm{a}$ ' refere-se à altura da planta (CLEMENT, 1995).

Além das características morfológicas, também foram avaliadas as seguintes características fisiológicas associadas às trocas gasosas: taxa de assimilação líquida de $\mathrm{CO}_{2}(A)$; condutância estomática $\left(g_{s}\right)$; taxa de transpiração $(E)$ e déficit de pressão de vapor (VpdL). Além desses parâmetros, a relação entre a concentração mesofílica e a ambiental de $\mathrm{CO}_{2}\left(C / C_{a}\right)$; a eficiência intrínseca no uso da água $\left(A / g_{s}\right)$; e a eficiência no uso da água $(A / E)$ foram posteriormente calculados. As mensurações foram realizadas de forma padronizada no folíolo médio da primeira ráquis totalmente expandida (PIRES et al., 2013), com o auxílio de um analisador de gás por infra-vermelho (IRGA) (Licor $6400 \mathrm{XL}$ ) sob condições atmosféricas naturais $(\sim 380-390 \mathrm{ppm}$ de $\mathrm{CO}_{2}$ ). As avaliações foram realizadas sob luz saturante $\left(1500 \mu \mathrm{mol} \mathrm{m}^{-2} \mathrm{~s}^{-1}\right)$. Durante as medições, a temperatura ambiente variou entre 23 a $33,7^{\circ} \mathrm{C}$, e a temperatura da folha entre 28 e $33^{\circ} \mathrm{C}$. A umidade relativa do ar era de cerca de $80 \%$ no momento das mensurações. Todas as avaliações foram realizadas entre $09 \mathrm{~h}$ e $11 \mathrm{~h}$ da manhã, as leituras registradas após os valores de $A$ e $\mathrm{g}_{\mathrm{s}}$ estabilizarem e quando o coeficiente de variação, medido pelo LiCor $6400 \mathrm{XT}$, era menor que 1,0 .

Os dados coletados foram submetidos à análise de variância (ANOVA) e a existência de variabilidade para as características avaliadas foi 
testada por meio do teste $\mathrm{F}$, a $5 \%$ de probabilidade. Posteriormente, foram estimados os seguintes parâmetros genéticos: herdabilidade $\left(\mathrm{h}^{2}\right)$, coeficiente de variação genético $(\mathrm{CVg})$ e coeficiente de variação ambiental (CVa). Os dados obtidos foram ainda correlacionados entre si por meio da correlação de Pearson. A distância generalizada Mahalanobis $\left(D^{2}\right)$ foi utilizada para se estabelecer a matriz de dissimilaridade genética (GS) entre as famílias avaliadas com base nas características morfológicas e fisiológicas. As famílias foram então agrupadas por meio do método UPGMA (Unweighted Pair Group Method with Arithmetic Mean). A importância relativa dos caracteres em relação à divergência genética entre as famílias foi estudada por meio do método de Singh (SINGH, 1981). Todas as análises foram realizadas utilizando módulos no software Genes (CRUZ, 2013).

\section{RESULTADOS E DISCUSSÃO}

Verificou-se a existência de variabilidade genética para as características morfológicas avaliadas (Tabela 2). As estimativas de parâmetros genéticos para essas características são apresentadas na tabela 2 . As estimativas de herdabilidade variaram entre 50,24 e 71,9\% (altura e comprimento da ráquis, respectivamente). De maneira geral, esses valores podem ser considerados elevados e indicam que existe um forte controle genético da arquitetura das plantas. Quando esses dados são analisados conjuntamente com aqueles obtidos para os coeficientes de variação genético (CVg) e ambiental (CVa) (cuja razão CVg/ CVa na maioria dos casos se aproxima de 0,5), verifica-se que o melhoramento da espécie para características morfológicas é possível de ser realizado por meio da seleção de genótipos promissores. A seleção de plantas com arquitetura mais favorável ao manejo, a existência de variabilidade genética para características morfológicas, e alta herdabilidade indicam que o melhoramento poderá se dar com alto poder seletivo e com alta expectativa de ganho genético. Estudos com estimativas de herdabilidade e outros parâmetros genéticos para caracteres morfo-agronômicos em palmáceas são escassos, de

Tabela 2 - Análise de variância (ANOVA) e parâmetros genéticos associados às características morfológicas de interesse de Macaúba. GL graus de liberdade; Altura da planta ; CR - comprimento da ráquis; LR - largura da ráquis; NR - número de ráquis; ATR - área total da ráquis; Taxa de assimilação líquida de $\mathrm{CO}_{2}(A)$; condutância estomática $\left(g_{\mathrm{s}}\right)$; taxa de transpiração $(E)$; déficit de pressão de vapor $(\mathrm{VpdL})$; relação entre a concentração mesofílica e a ambiental de $\mathrm{CO}_{2}\left(\mathrm{C}_{\mathrm{i}} / \mathrm{C}_{\mathrm{a}}\right)$; eficiência intrínseca no uso da água $\left(\mathrm{A} / \mathrm{g}_{\mathrm{s}}\right)$; eficiência no uso da água $(\mathrm{A} / \mathrm{E}) ; \mathrm{h}^{2}$ - herdabilidade; $\mathrm{CVg}(\%)$ - coeficiente de variação genético; CVa $(\%)$ - coeficiente de variação ambiental e $\operatorname{CVr}(\%)$ - coeficiente de variação residual.

\begin{tabular}{|c|c|c|c|c|c|c|c|}
\hline Fonte de Variação & GL & Altura & $\mathrm{CR}$ & LR & NR & ATR & $A$ \\
\hline Blocos & 4 & 0,32 & 0,04 & 0 & 1,47 & 1,46 & 30,12 \\
\hline Genótipos & 14 & $0,94 *$ & $0,18 * *$ & $0,24 * *$ & $1,59 * *$ & $4,22 *$ & $5,46 \mathrm{~ns}$ \\
\hline Resíduo & 56 & 0,04 & 0,05 & 0 & 0,54 & 2,08 & 6,50 \\
\hline Média & & 1,78 & 1,88 & 0,82 & 6,8 & 10,86 & 21,06 \\
\hline Máximo & & 2,39 & 2,64 & 1,11 & 10 & 14,94 & 28,86 \\
\hline Mínimo & & 1,19 & 1,29 & 0,59 & 4,33 & 6,89 & 15,14 \\
\hline$h^{2}(\%)$ & & 50,24 & 71,9 & 68,18 & 65,62 & 50,6 & - \\
\hline CVg $(\%)$ & & 5,45 & 8,73 & 6,95 & 6,72 & 6,01 & 12,1 \\
\hline CVa (\%) & & 12,13 & 12,21 & 10,62 & 10,88 & 13,29 & - \\
\hline $\operatorname{CVr}(\%)$ & & 0,44 & 0,71 & 0,65 & 0,61 & 0,45 & - \\
\hline Fonte de Variação & GL & $g \mathrm{~s}$ & $E$ & VpdL & $\mathrm{Ci} / \mathrm{Ca}$ & $\mathrm{A} / \mathrm{gs}$ & $\mathrm{A} / \mathrm{E}$ \\
\hline Blocos & 4 & 0,62 & 15,47 & 1,17 & 0,04 & 1556,27 & 6,18 \\
\hline Genótipos & 14 & $0,05 \mathrm{~ns}$ & $0,46 \mathrm{~ns}$ & $0,02 \mathrm{~ns}$ & $0,00 \mathrm{~ns}$ & $97,34^{*}$ & $0,15 \mathrm{~ns}$ \\
\hline Resíduo & 56 & 0,47 & 0,40 & 0,00 & 0,00 & 47,86 & 0,18 \\
\hline Média & & 0,49 & 4,83 & 1,08 & 0,72 & 51,04 & 4,59 \\
\hline Máximo & & 1,9 & 7,1 & 1,65 & 0,92 & 69,25 & 5,92 \\
\hline Mínimo & & 0,22 & 2,81 & 0,41 & 0,63 & 12,46 & 3,09 \\
\hline$h^{2}(\%)$ & & 18,18 & 13,65 & 61,28 & 37,66 & 50,82 & - \\
\hline CVg (\%) & & 44,46 & 13,08 & 9,06 & 4,49 & 13,55 & 9,48 \\
\hline CVa (\%) & & 9,37 & 2,32 & 5,1 & 1,56 & 6,16 & - \\
\hline CVr (\%) & & 0,21 & 0,17 & 0,56 & 0,34 & 0,45 & - \\
\hline
\end{tabular}

** significativo a $1 \% \mathrm{e} *$ significativo a $5 \%$ de probabilidade. ${ }^{\text {ns }}$ não significativo a $5 \%$ de probabilidade pelo teste $\mathrm{F}$. 
modo que uma comparação pormenorizada entre os resultados obtidos neste estudo com outros é difícil. BERTON (2013), trabalhando com plantas jovens de macaúba e avaliando medidas biometrias constataram que as herdabilidades no sentido restrito para tais características variaram entre 75 a $84 \%$. Tendo em vista as estimativas aqui relatadas e aquelas relatadas por BERTON (2013), é possível perceber que a macaúba é uma palmeira que apresenta elevados níveis de variabilidade genética. Esse fato não ocorre com todas as palmeiras. Note que SOH et al. (2003) relatam herdabilidades variando de 22 a $36 \%$ para caracteres produtivos em palma de óleo (Elaeis guineensis). A disparidade de valores obviamente pode estar relacionada ao nível de melhoramento das espécies. Enquanto a macaúba é uma espécie não domesticada, a palma de óleo já vem sendo sistematicamente melhorada há décadas (GOMES JUNIOR et al., 2013).

Ao contrário do observado para as características morfológicas, as famílias de meioirmãos estudadas praticamente não apresentam variabilidade para características fisiológicas (estas diferiram apenas para $A / g_{s}$ ) (Tabela 3). Para essa característica, $\mathrm{a} \mathrm{h}^{2}$ foi estimada em aproximadamente $50 \%$ e o $\mathrm{CVg} / \mathrm{CVa}$ em 0,45 . A constatação de existência de variabilidade para a eficiência no uso da água, no entanto, é bastante promissora, tendo em vista a possibilidade de se selecionar genótipos mais tolerantes ao estresse hídrico ou que fazemuso eficiente da água. Considerando-se que a área de ocorrência da macaúba é a região centro-oeste do Brasil, futuros plantios da espécie devem ocorrer em áreas de cerrado, que são caracterizadas por longos períodos de seca durante o ano. Desse modo, genótipos mais tolerantes a estresse hídrico deverão apresentar vantagem competitiva em relação a genótipos sensíveis.

A não existência de variabilidade para outros parâmetros fisiológicos pode ser atribuída à pequena amostragem. $\mathrm{O}$ teste de progênie avaliado contém famílias oriundas de apenas três estados: Minas Gerais, Goiás e Distrito Federal. Como a distribuição da espécie é muito mais ampla (MANFIO et al., 2012), é possível que, ao se amostrar uma maior quantidade de plantas em um número maior de regiões, seja possível identificar diferenças significativas. ZHU et al. (2010), entretanto, demonstraram que os incrementos em produtividade obtidos via melhoramento da maioria das culturas não se deu pelo aprimoramento de características fisiológicas (como, por exemplo, capacidade de fixação de $\mathrm{CO}_{2}$ ), mas sim pela melhoria dos componentes de produção (i.e. caracteres morfológicos). Sendo assim, mesmo não tendo sido verificada variabilidade para características fisiológicas, como vários estudos já demonstraram a existência de variabilidade genética para características morfológicas (MANFIO et al., 2012, BERTON, 2013), a perspectiva de melhoramento da macaúba é promissora.

No que concerne ao relacionamento das características avaliadas, os dados deste estudo fornecem evidências de que as características morfológicas em avaliação são relacionadas entre si, bem como as características fisiológicas. Estes resultados indicam que, em programas de melhoramento genético de macaúba, há a possibilidade de se realizar a seleção indireta para

Tabela 3 - Estimativas de correlação de Pearson entre variáveis morfológicas e fisiológicas em Macaúba. $A$ - Taxa de assimilação líquida de $\mathrm{CO}_{2} ; g_{\mathrm{s}}$ - condutância estomática; $E$ - taxa de transpiração; VpdL - déficit de pressão de vapor; $C \mathrm{i} / C$ a - relação entre a concentração mesofílica e a ambiental de $\mathrm{CO}_{2} ; A / g_{\mathrm{s}}$ - eficiência intrínseca no uso da água; $A / E$ - eficiência no uso da água; $\mathrm{H}$ altura; CR - comprimento da ráquis; LR - largura da ráquis; NR - número de ráquis; ATR - área total da ráquis.

\begin{tabular}{|c|c|c|c|c|c|c|c|c|c|c|c|c|}
\hline Variáveis & A & Gs & $\mathrm{E}$ & VpdL & $\mathrm{Ci} / \mathrm{C}$ & $\mathrm{A} / \mathrm{gs}$ & $\mathrm{A} / \mathrm{E}$ & $\mathrm{H}$ & $\mathrm{CR}$ & LR & NR & ATR \\
\hline A & 1 & $-0,10$ & $0,67 * *$ & $0,32 * *$ & $-0,23 *$ & 0,13 & $-0,17$ & $-0,20$ & $-0,12$ & $-0,20$ & 0,07 & $-0,19$ \\
\hline gs & & 1 & 0,20 & $-0,61 * *$ & $0,84 * *$ & $-0,85 * *$ & $-0,39 * *$ & 0,06 & 0,08 & 0,11 & 0,07 & 0,06 \\
\hline $\mathrm{E}$ & & & 1 & $0,49 * *$ & 0,04 & $-0,13$ & $-0,82 * *$ & $-0,12$ & $-0,15$ & $-0,18$ & 0,07 & $-0,12$ \\
\hline VpdL & & & & 1 & $-0,77 * *$ & $0,73^{* *}$ & $-0,36^{* *}$ & $-0,14$ & $-0,20$ & $-0,19$ & $-0,07$ & $-0,14$ \\
\hline $\mathrm{Ci} / \mathrm{Ca}$ & & & & & 1 & $-0,98 * *$ & $-0,27 *$ & 0,12 & 0,10 & 0,10 & 0,13 & 0,12 \\
\hline $\mathrm{A} / \mathrm{gs}$ & & & & & & 1 & $0,33 * *$ & $-0,13$ & $-0,13$ & $-0,12$ & $-0,13$ & $-0,13$ \\
\hline $\mathrm{A} / \mathrm{E}$ & & & & & & & 1 & 0,03 & 0,10 & 0,08 & $-0,03$ & 0,04 \\
\hline $\mathrm{H}$ & & & & & & & & 1 & $0,82^{* *}$ & $0,69^{* *}$ & $0,22 *$ & $0,99 * *$ \\
\hline CR & & & & & & & & & 1 & $0,83^{* *}$ & 0,10 & $0,82 * *$ \\
\hline LR & & & & & & & & & & 1 & $-0,07$ & $0,69 * *$ \\
\hline NR & & & & & & & & & & & 1 & 0,22 \\
\hline ATR & & & & & & & & & & & & 1 \\
\hline
\end{tabular}

**,* Correlação significativa ao nível de 1 e 5\% de probabilidade pelo teste t, respectivamente. 
algumas características, a exemplo da altura da planta, que se correlaciona com o comprimento de ráquis ou largura de ráquis. Se essa correlação mantiver-se-se ao longo dos anos, a seleção de plantas de menor porte (característica interessante por permitir que palmeiras sejam mais facilmente manejadas por um período maior de tempo) poderá ser realizada em idade precoce por meio da mensuração da ráquis. Situação análoga ocorre no melhoramento da palma de óleo, na qual, recentemente, vem se buscando introduzir germoplasma de Elaeis oleifera, dado ao menor porte e menor incremento anual em altura (GOMES JUNIOR et al., 2013). Um ponto importante que ainda precisa ser investigado é se árvores de menor porte são tão produtivas quanto as árvores maiores. Como a capacidade fotossintética, medida pela taxa de assimilação líquida de $\mathrm{CO}_{2}$, não se correlacionou significativamente com a altura das plantas, nem com as características de arquitetura da planta, este trabalho provê evidências de que plantas de menor porte podem fixar o $\mathrm{CO}_{2}$ atmosférico com a mesma eficiência de plantas mais altas. Ainda no que tange à análise de correlação, verifica-se que não há evidência de relacionamento entre características fisiológicas e morfológicas. FLOOD et al. (2011) haviam sugerido que parâmetros fisiológicos poderiam ser utilizados como marcadores para características morfológicas de complexa e/ou difícil mensuração, uma vez que, em muitos casos, existe ligação direta entre tais parâmetros. A não existência de correlação entre características fisiológicas e morfológicas não permite, no entanto, que tal abordagem seja utilizada no melhoramento da macaúba. Tendo em vista, entretanto, o fato de a espécie ser nativa e de apresentar ampla diversidade fenotípica, talvez uma maior amostragem possa revelar genótipos contrastantes, tanto para características morfológicas quanto para características fisiológicas, sendo, nesse caso, plausível que algum relacionamento entre essas características seja verificado. Cabe ressaltar que a macaúba é uma espécie de ciclo longo, portanto, a repetibilidade das características pode não ser elevada em idade juvenil. Isso porque, com o desenvolvimento das plantas, é esperado que o metabolismo se altere. Nesse caso, um número de medidas mínimo, estabelecido com base no coeficiente de repetibilidade, deve ser necessário para se verificar o real relacionamento entre características complexas. Nesse sentido, MANFIO et al. (2012), estudando características biométricas do fruto da macaúba, verificaram que os coeficientes de repetibilidade variaram de 0,68 a 0,99 para diversas características. Coeficientes de repetibilidade temporais, contudo, ainda não foram determinados para nenhuma característica da macaúba. Além disso, interações complexas entre genótipos e ambiente podem influenciar na expressão das características morfológicas e fisiológicas. Assim, há possibilidade de que haja variações nos coeficientes de correlação estimados em anos distintos.

As dissimilaridades $\left(\mathrm{D}^{2}\right)$ entre os acessos variaram de 2,81 a 32,82, com média de 11,40. Os maiores valores foram registrados entre as famílias "CPAC-03" e "RP003", que foram coletadas em Formosa - GO - e Rio Paranaíba MG -, respectivamente. Por outro lado, as famílias "Acesso-280" e "EPAMIG-02" foram os menos distantes geneticamente, tendo sido ambas coletadas em Minas Gerais, em municípios diferentes (Tabela 1). Para uma melhor avaliação da diversidade genética das famílias, realizou-se posteriormente a hierarquização destas pelo método do UPGMA (Figura 1). Notase uma clara tendência de agrupamento de famílias relacionadas. As famílias denominadas pelo acrônimo "CPAC" (por terem sido originalmente coletadas em mantidas pela Embrapa Cerrados), por exemplo, tenderam a se agrupar, com a exceção da família CPAC01, que se agrupou junto a uma família da EPAMIG e a dois acessos do BAG de Macaúba, mantido pela Universidade Federal de Viçosa (UFV); e da família CPAC-03 que não se agrupou com as demais. Com base no ponto de corte correspondente à dissimilaridade genética média $\left(\mathrm{D}^{2}=11,40\right)$, o dendrograma gerado permitiu a separação das famílias em três grupos. $\mathrm{O}$ primeiro grupo compreende as famílias com acrônimo RP(Rio Paranaíba), os acessos do banco de germoplasma da UFV, as famílias da EPAMIG e apenas uma família da Embrapa Cerrados. O segundo grupo é composto por seis famílias do CPAC e um terceiro grupo por uma única família também do CPAC. Esse resultado é coerente também com o agrupamento gerado pelo método de otimização de Tocher (SHARMA, 2006; CRUZ et al., 2011), que indicou também existência de três grupos. No caso do método de otimização, entretanto, houve maior tendência de concentração de famílias no grupo 1, que, além daquelas já indicadas pelo UPGMA, também inclui as famílias CPAC-02 e CPAC-04 (i.e. concentra $\sim 73 \%$ das famílias). De qualquer modo, esses resultados indicam que as famílias mantidas pela Embrapa Cerrados não são proximamente relacionadas às famílias mantidas pela UFV ou EPAMIG. Isso é interessante do ponto de vista de melhoramento, pois pode indicar a existência 


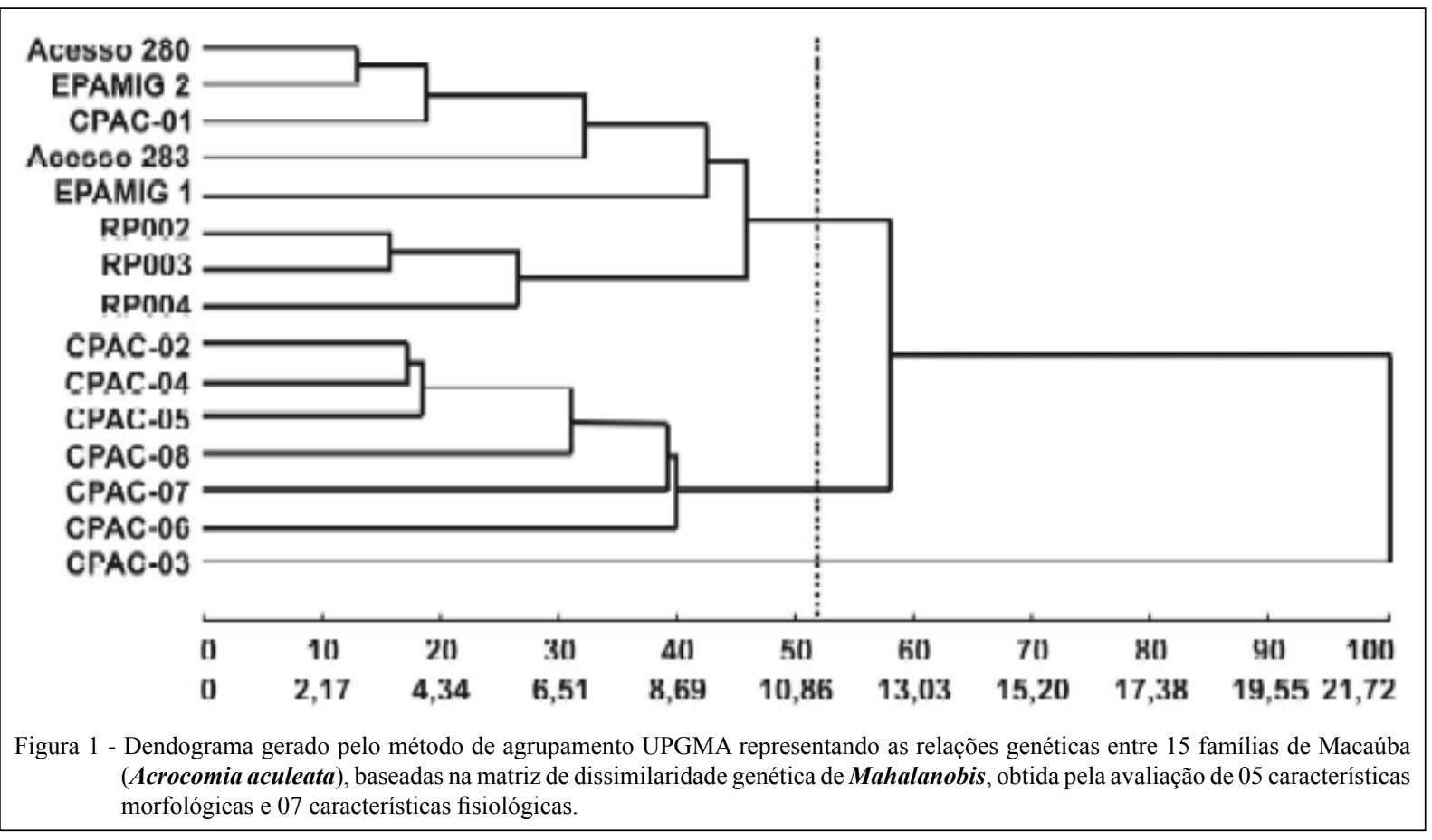

de pools gênicos distintos que poderão ser explorados posteriormente por meio de hibridações controladas em esquemas de seleção recorrente recíproca (SRR). A tendência de materiais genéticos se agruparem em grupos gênicos distintos, que podem ser explorados para fins de melhoramento, também foi verificada em outra palmeira, como o açaizeiro (OLIVEIRA et al., 2003). Além disso, tendo em vista a verificação de que a família CPAC-03 é a mais distinta entre aquelas avaliadas, para aumentar a diversidade na população de melhoramento, deve-se buscar coletar um maior número de plantas provenientes da região de Formosa - GO.

No que diz respeito à importância relativa dos caracteres para a diferenciação das famílias, as características que apresentaram as maiores contribuições relativas para a divergência genética foram: a eficiência intrínseca no uso da água ( $A$ / $g_{s}$ ) e comprimento da ráquis (CR) (Figura 2). Essas características contribuíram relativamente em 24.73 e $19.65 \%$, respectivamente, para a divergência das famílias. Essas duas características foram identificadas como significativas, no que diz respeito à avaliação das famílias (Tabelas 2 e 3), e apresentam herdabilidades moderadamente elevada e elevada, respectivamente. Isso indica que avaliação destas características será importante em etapas mais avançadas dos programas de melhoramento da espécie, dada a possibilidade real de obtenção de ganhos por seleção e a contribuição destas para a dissimilaridade das famílias. Já as características ATR e $E$ foram as características que menos contribuíram para a divergência das famílias $(0.49$ e $0.76 \%)$ (Figura 2$)$. Por apresentarem menores contribuições para a dissimilaridade, pode-se dar menor ênfase no momento das avaliações posteriores a essas características. Por fim, verifica-se, em consonância aos resultados apresentados na tabela 3 , que a fotossíntese não apresenta grande importância relativa na diferenciação das famílias. Isso novamente ressalta o fato de que os ganhos incrementais de produtividade para a espécie deverão ser obtidos mais pela melhoria dos componentes de produção (i.e. caracteres morfológicos) do que por características fisiológicas, como ocorreu para a maioria das culturas agrícolas (ZHU et al., 2011).

\section{CONCLUSÃO}

Existe variabilidade para as características morfológicas de macaúba que pode ser explorada para melhoramento genético da espécie; porém, não se verificou variabilidade para a maioria dos caracteres fisiológicos. As famílias avaliadas agrupam-se em três grupos distintos, sendo que a família CPAC-03 não se agrupa com as demais, podendo ser considerada a mais divergente, com base na análise combinada de características morfológicas e fisiológicas. A eficiência intrínseca no uso da água $\left(A / g_{s}\right)$ e o comprimento da ráquis $(\mathrm{CR})$ são as características que mais contribuem para dissimilaridade das famílias avaliadas. 


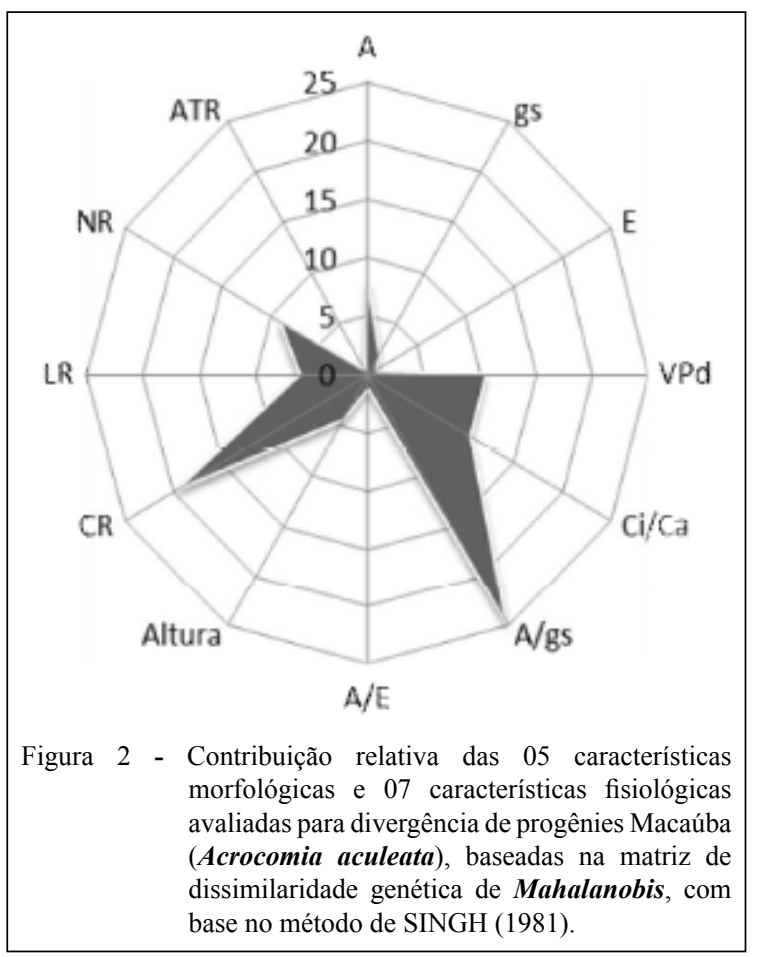

\section{AGRADECIMENTOS}

À Financiadora de Estudos e Projetos (FINEP) e ao Conselho Nacional de Desenvolvimento Científico e Tecnológico (CNPq), pelo financiamento do projeto PROPALMA, e a Rodrigo F. Santos, Jean C. Alekcevetch, Júlio C. Marana, Laíse T. Costa e Genivaldo J. Fonseca, pelo auxílio na avaliação das progênies.

\section{REFERÊNCIAS}

AGENCIA NACIONAL DE PETRÓLEO, Gás Natural e Biocombustíveis (ANP). Boletim mensal de biodiesel, junho 2014. Anais eletrônicos... Disponível em: $<$ http://www.anp.gov. br/biocombustiveis>. Acesso em: 01 jul. 2014.

BERTON, L.H.C. Avaliação de populações naturais, estimativas de parâmetros genéticos e seleção de genótipos elite de macaúba (Acrocomia aculeata). 2013. 154f. Dissertação (Mestrado em Melhoramento genético de plantas) - Instituto Agronômico de Campinas, Campinas, SP. Disponível em: $<$ http://www.iac.sp.gov. br/areadoinstituto/posgraduacao/dissertacoes/1270809.pdf $>$. Acesso: 22 jan 2015.

CLEMENT, C.R. Growth and genetic analysis of pejibaye (Bactris gasipaes Khunth, Palmae) in Hawaii. 1995. $221 \mathrm{f}$. PhD Dissertation - University of Hawaii at Manoa, Honolulu, HI. Disponível em: <https://www.inpa.gov.br/cpca/charles/charlescabs-msc-phd.html>. Acesso 22 jan 2015.

CRUZ, C.D. GENES - a software package for analysis in experimental statistics and quantitative genetics. Acta Scientiarum. Agronomy (Online), v.35, p.271-276, 2013. Disponível em:
$<$ http://www.scielo.br/pdf/asagr/v35n3/v35n3a01>. Acesso em 21 jan 2015. doi: 10.4025/actasciagron.v35i3.21251.

FLOOD, P.J. et al. Natural genetic variation in plant photosynthesis. Trends in Plant Science, v.16, n.6, p.327-335, 2011. Disponível em: <http://dx.doi.org/10.1016/j.tplants.2011.02.005>. Acesso em 21 jan 2015. doi: 10.1016/j.tplants.2011.02.005.

GOMES, F.P. et al. Photosynthetic limitations in leaves of young Brazilian green dwarf coconut (Cocos nucifera L. 'nana') palm under well-watered conditions or recovering from drought stress. Environment Experimental Botany, v.62, p.195-204, 2008. Disponível em: $<$ http://jxb.oxfordjournals.org/content/60/13/3737. full $>$. Acesso em 21 jan 2015. doi: 10.1093/jxb/erp216.

GOMES JUNIOR, R.A. et al. Evaluation of interspecific hybrids of palm oil reveals great genetic variability and potential selection gain. Industrial Crops and Products (Print), v.52, p.512-518, 2014. Disponível em: <http://www.sciencedirect.com/science/ article/pii/S0926669013005888>. Acesso 22 jan 2015. doi: 10.1016/j.indcrop.2013.10.036.

LAVIOLA, B.G.; ALVES, A.A. Matérias primas oleaginosas para biorrefinarias. In: VAZ Jr, S. (Org.). Biorrefinarias: cenários e perspectivas. Brasília: Embrapa Agroenergia, 2011 p.29-34.

MANFIO, C.E. et al. Avaliação de progênies de macaúba na fase juvenil e estimativas de parâmetros genéticos e diversidade genética. Pesquisa Florestal Brasileira (Online), v.32, p.63-68, 2012. Disponível em: <http://pfb.cnpf.embrapa.br/pfb/index.php/ pfb/article/download/283/247>. Acesso em 22 jan 2015.

OLIVEIRA, M.S.P. et al. Parâmetros genéticos para caracteres germinativos em vinte progênies de açaizeiro promissoras para palmito. Boletim de Pesquisa Florestal, v.46, p.105-113, 2003.

PIMENTEL, L.D. et al. Recomendação de adubação e calagem para o cultivo da macaúba: 1a aproximação. Informe Agropecuário v.32, p.20-30, 2011.

SHARMA, J.R. Statistical and biometrical techniques in plant breeding. Delhi: New Age International, 2006. 432p.

SINGH, D. The relative importance of characters affecting genetic divergence. The Indian Journal of Genetics e Plant Breeding, v.41, p.237-245, 1981.

SOH, A.C. et al. Estimates of within family genetic variability for clonal selection in oil palm. Euphytica, v.133, p.147-163, 2003. Disponível em: <http://link.springer.com/article/10.1023\%2FA\% 3A1025582214696>. Acesso em 22 jan 2015.

TEIXEIRA, L.C. Potencialidades de oleaginosas para produção de biodiesel. Revista Informe Agropecuário, v.26, n.229. p.18$27,2005$.

ZHU, X-G. Improving photosynthetic efficiency for greater yield. Annual Review Plant Biology, v.61, p.235261, 2010. Disponível em: <http://www.annualreviews. org/doi/abs/10.1146/annurev-arplant-042809-112206>. Acesso em 22 jan 2015. doi: 10.1146/annurevarplant-042809-112206. 